\title{
ANALISIS KAJIAN POTENSI PROSPEK USAHA JAJANAN MALAM HARIDI KOTA MEDAN
}

\author{
Oleh: \\ Nawary Saragih, SE, M.Si
}

\begin{abstract}
The purpose of this study was to: (1). Describe the main attraction of tourism potential prospects night snacks in Medan. (2). Examines the characteristics of tourists who visit the centers of business prospects night snacks Medan. (3). Assessing the behavior patterns of tourists visiting in the centers of business prospects night snacks Medan. (4). Assessing the perception of tourists to the potential business prospects night snacks in Medan. In order for the city of Medan can become a tourist destination evening snack can be achieved, the necessary development strategies: (1). Menjaga and create the taste of food and beverages, for example Typical City of Medan. (2). Improve comfort and security of tourists in the centers of the evening snacks. (3). Maintain and enhance the overall area of cleanliness in the centers of the evening snacks. (4). Improve and maintain the appearance of employees in serving tourists. (5). Prices of food and beverages made cheap but the quality is maintained.

To take advantage of the vast opportunities, the local government of Medan city are expected to participate more intensively to support the development of snacks in the evening in the city of Medan. The existence of policies and extension is considered to be very helpful in the completion of cooking the evening snacks. In addition, local governments also need to facilitate the growth and development of tourism products industry night snacks with supporters as hardwares local regulations that can accommodate the interests of employers / principals hari.Terkait evening snacks of local government funding can also be a bridge to help the funding recommendation to the entrepreneur evening snacks through cooperatives and banks, one of which is a government-owned bank, Bank of North Sumatra.
\end{abstract}

Keywords: Potential prospects, business hawker night

\section{PENDAHULUAN}

Kekayaan alam, budaya dan manusia di Indonesia sebagai Negara kepulauan sangat besar dan beragam yang merupakan sumber kepariwisataan dan berpotensi besar sebagai daya tarik pariwisata. Pariwisata menjadi sektor andalan Indonesia dalam pemasukan devisa Negara, peningkatan pendapatan masyarakat, dan untuk meningkatkan Pendapatan Asli Daerah (PAD) di berbagai kabupaten/kota maupun provinsi.

Trend wisatawan sekarang yang datang ke suatu daerah wisata untuk mencari atau berburu makanan khas daerah tersebut menjadi peluang besar bagi daerah.Mereka tidak segan-segan membayar mahal untuk menikmati suatu hidangan. Perubahan gaya hidup masyarakat juga telah terjadi, mereka makan tidak hanya untuk mengenyangkan perut saja, tetapi mereka juga mencari suasana dan pelayanan yang prima sebagai bagian dari sajian makanan yang dipesan. Banyak wisatawan yang menyempatkan waktu berburu makanan dan minuman khas daerah tujuan di sela-sela kegiatannya berwisata, termasuk wisatawan yang berkunjung ke Sumatera Utara pada umumnya dan Kota Medan pada khususnya.

Kota Medan sebagai ibu kota Provinsi Sumatera Utara yang memiliki banyak lembaga pendidikan telah mampumendatangkan penduduk dari luar Kota Medan bahkan luar Daerah Provinsi Sumatera Utara untuk datang atau tinggal di Kota Medan. Hal itu menyebabkankeberadaan tempat makan (warung/restoran/rumah makan) dapat berkembang dengan baik.Namun demikian, para pendatang yang sebagian besar adalah 
pelajar dan mahasiswa dariberbagai wilayah di Pulau Sumatera tidak semua cocok dengan selera masakan Kota Medan.Oleh karena itu para pemilik warung makan atau restoran mengembangkanproduk makanannya menyesuaikan dengan selera para pendatang, sehingga semakin beragamjenis dan rasa masakan di Kota Medan.

Banyak tempat-tempat yang menjadi pusat penjualan makanan dan minuman malam hari seperti di Merdeka Walk, Dr.Mansyur, Ring Road, Ramadhan Fair, Pagaruyung, Warkop Elisabeth, TST Jl Puri dan Halat, Jl. Gurupatimpus, Jl Majapahit, Pasar Merah Square, Amaliun Food Court, Jl.Semarang, Selat Panjang dan lainnya. Banyaknya sentrasentra usaha jajanan malam hari di wilayah Kota Medan menjadipeluang untuk menjadikan Kota Medan sebagai Daerah Tujuan Wisata Kuliner.Namundemikian ketersediaan pusatpusat penjualan makanan tersebut tidak lepas dari berbagaimasalah seperti kebersihannya, menu yang ditawarkan, pemasarannya, harga yang di patokoleh pedagang, suasana kurang nyaman.Oleh karena itu perlu dicari solusi agar potensi wisata jajanan malam hari di Kota Medan dapat dioptimalkan sesuai dengan visi Kota Medan Kota Medan menjadiKota Metropolitan yang berdaya Saing, Nyaman, Peduli, dan Sejahtera".

\section{METODE PENELITIAN}

Metode yang digunakan adalah metode penelitian deskriptif kuantitatif dengan pendekatan survei.Lokasi penelitian adalah sentra-sentra jajanan malam hari di Kota Medan yang dianggap dapat mewakili masing-masing wilayah Kota Medan. Oleh karena itu dipilih sentra-sentra kuliner meliputi Merdeka Walk, Dr.Mansyur, Ring Road, Ramadhan Fair, Pagaruyung, Warkop Elisabeth, TST Jl Puri dan Halat, Jl. Gurupatimpus, Jl Majapahit, Selat Panjang.Populasi dalam kajian ini adalah seluruh sentra-sentra jajanan malam hari yang ada di Kota Medan.

Sampel penelitian dengan menggunakan teknik Accidental Purposiveyang ditentukan jumlahnya melalui Kuota Sampling.Penetapan jumlahsampel dengan rmenggunakan Panduan Audit Kinerja Pemerintah kota dan Survei Kepuasan Masyarakatdengan rumus sebagai berikut:

$\mathrm{NZ}^{2 *} 0,25$

$\left[\mathrm{d}^{2 *}(\mathrm{~N}-1)\right]+\left[\mathrm{Z}^{2 *} 0,25\right]$

Keterangan : $\mathrm{N}=$ jumlah populasi; $\mathrm{d}=$ confidence interval 0,$05 ; \mathrm{Z}=$ jumlah unit standar deviasi distribusi sampling yang berkorepsondensi dengan tingkat kepercayaan 95\% yaitu 1,96). Berdasarkan rumus, maka jumlah sampel pada kajian ini berjumlah 384 responden, masing-masing lokasi penelitian diambil jumlah sample secara proporsional.

Dari Kegiatan pengumpulan data dalam penelitian ini dengan menggunakan kuesioner yang disampaikan kepengunjung hasilnya sebagai berikut:

\section{Hasil Uji Validitas dan Realiabilitas}

Dengan menggunakan Statistical Program for Social Science (SPSS) Version 16,0, maka diperoleh hasil uji validitas dan realiabilitas instrumen yang disajikan pada tabel berikut: 
Tabel 1: Hasil Uji Validasi dan Realiabilitas

\begin{tabular}{|c|c|c|c|c|}
\hline \multirow{2}{*}{$\begin{array}{l}\text { Faktor-Faktor Yang Mempengaruhi } \\
\text { Prospek Usaha Jajanan Malam Hari }\end{array}$} & \multirow{2}{*}{$\mathrm{r}$} & \multirow{2}{*}{ Ket } & Alpha & \multirow{2}{*}{ Ket } \\
\hline & & & Cronbach & \\
\hline Variasi pilihan Makanan dan Minuman & 0.413 & Valid & 0.738 & Realiabel \\
\hline Rasa Makanan dan Minuman & 0.354 & Valid & 0.740 & Realiabel \\
\hline Presentase Makanan dan Minuman & 0.390 & Valid & 0.737 & Realiabel \\
\hline Ukuran Porsi Makanan dan Minuman & 0.364 & Valid & 0.744 & Realiabel \\
\hline Kecepatan Pelayanan & 0.508 & Valid & 0.733 & Realiabel \\
\hline Ketepatan Pelayanan & 0.490 & Valid & 0.734 & Realiabel \\
\hline Fasilitas Pemesanan Tempat Duduk & 0.770 & Valid & 0.725 & Realiabel \\
\hline Ketersediaan Pembayaran & 0.419 & Valid & 0.737 & Realiabel \\
\hline Jam Operasional & 0.668 & Valid & 0.729 & Realiabel \\
\hline Perilaku Karyawan Siap Membantu & 0.424 & Valid & 0.738 & Realiabel \\
\hline Karyawan yang penuh perhatian & 0.421 & Valid & 0.737 & Realiabel \\
\hline Penampilan karyawan yang bersih & 0.791 & Valid & 0.726 & Realiabel \\
\hline Daftar menu bersih dan rapi & 0.571 & Valid & 0.732 & Realiabel \\
\hline Kebersihan area & 0.516 & Valid & 0.735 & Realiabel \\
\hline Value for money & 0.732 & Valid & 0.727 & Realiabel \\
\hline Pemberian diskon & 0.691 & Valid & 0.726 & Realiabel \\
\hline Happy haur & 0.533 & Valid & 0.733 & Realiabel \\
\hline Pencahayaan yang tepat & 0.672 & Valid & 0.729 & Realiabel \\
\hline Penataan meja makanan & 0.601 & Valid & 0.731 & Realiabel \\
\hline Kenyamanan furniture & 0.580 & Valid & 0.731 & Realiabel \\
\hline Hiburan & 0.754 & Valid & 0.730 & Realiabel \\
\hline
\end{tabular}

Berdasarkan1 di atas menunjukkan bahwa seluruh faktor-faktor yang mempengaruhi potensi prospek usaha jajanan malam hari di Kota Medan sudah valid dan reliable, karena nilai korelasi hitung telah lebih besar dari 0,30, dan nilai Alpha Cronbach telah lebih besar dari 0,60 .

\section{Analisis KMO and Barllett's Test}

Dari hasil pengolahan berdasarkan Statistical Program for Social Science (SPSS) Version 16,0, maka dari 24 pertanyaan yang dijawab oleh 73 responden dalam kuiesioner didapatkan hasil untuk KMO (Measure of Sampling Adequency) yang disajikan pada tabel berikut:

\section{Tabel 2: KMO and Barlett's Test}

\begin{tabular}{|c|c|c|}
\hline \multicolumn{3}{|c|}{ KMO and Bartlett's Test } \\
\hline $\begin{array}{l}\text { Kaiser-Meyer-Olkin Measure of } \\
\text { Sampling Adequacy. }\end{array}$ & & 0.7518 \\
\hline Bartlett's Test of Sphericity & Approx. Chi-Square & 1818.0196 \\
\hline & Df & 276 \\
\hline & Sig. & $8.255 \mathrm{E}-225$ \\
\hline
\end{tabular}

Dari tabel 2.di atas menunjukkan bahw nilai KMO sebesar 0,7518, telah melampaui angka 0,50 dan signifikan pada alpha 0,00. Dengan demikian seluruh variabel penelitian sudah layak dianalisis lebih lanjut. Dilihat dari angka chi-Square 1818,0196, berarti ke dua puluh satu faktor yang mempengaruhi potensi prospek usaha jajanan malam hari di Kota Medan dapat diterima pada tingkat signifikasi 1 persen.

\section{Anti Image Correlation}

Pada tabel Anti Image Marrices, di bagian Anti Image Coorelation menunjukkan angka yang membentuk diagonal yang menandakan besaran Measure Sampling Adequency (MSA) 
masing-masing variabel telah berada di atas 0,50 , yang berarti seluruh variabel masih bisa diprediksi untuk dianalisis lebih lanjut. Dari hasil pengujian tersebut diketahui bahwa semua variabel mempunyai korelasi yang cukup tinggi dengan vaiabel lain, sehingga analisis layak dilanjutkan dengan mengikutkan ke dua puluh satu faktor yang mempengaruhi potensi prospek usaha jajanan malam hari di Kota Medan.

\section{Communalites}

Communalities adalah jumlah varians dari suatu variabel yang bisa dijelaskan oleh faktor yang ada, dengan ketentuan semakin besar communalities, semakin erat hubungan variabel tersebut dengan faktor yang terbentuk. Hasil disajikan pada tabel berikut:

Tabel 3:Communalities

\begin{tabular}{|l|r|r|}
\hline \multicolumn{1}{|c|}{ Faktor-Faktor Yang Mempengaruhi } & \multirow{2}{*}{ Initial } & Extraction \\
\cline { 1 - 1 } \multicolumn{1}{|c|}{ Potensi Prospek Usaha Jajanan Malam Hari } & 1.000 & .665 \\
\hline Variasi pilihan Makanan dan Minuman & 1.000 & .733 \\
\hline Rasa Makanan dan Minuman & 1.000 & .639 \\
\hline Presentase Makanan dan Minuman & 1.000 & .602 \\
\hline Ukuran Porsi Makanan dan Minuman & 1.000 & .888 \\
\hline Kecepatan Pelayanan & 1.000 & .862 \\
\hline Ketepatan Pelayanan & 1.000 & .785 \\
\hline Fasilitas Pemesanan Tempat Duduk & 1.000 & .801 \\
\hline Ketersediaan Pembayaran & 1.000 & .810 \\
\hline Jam Operasional & 1.000 & .748 \\
\hline Perilaku Karyawan Siap Membantu & 1.000 & .665 \\
\hline Karyawan yang penuh perhatian & 1.000 & .854 \\
\hline Penampilan karyawan yang bersih & 1.000 & .815 \\
\hline Daftar menu bersih dan rapi & 1.000 & .689 \\
\hline Kebersihan area & 1.000 & .724 \\
\hline Value for money & 1.000 & .675 \\
\hline Pemberian diskon & 1.000 & .656 \\
\hline Happy haur & 1.000 & .626 \\
\hline Pencahayaan yang tepat & 1.000 & .838 \\
\hline Penataan meja makanan & 1.000 & .815 \\
\hline Kenyamanan furniture & 1.000 & .859 \\
\hline Hiburan & & \\
\hline
\end{tabular}

Dari tabel 3. di atas nampak bahwa besarnya varians setiap variabel yang dapat dijelaskan oleh faktor yang terbentuk adalah sebesar yang ada pada kolom dari Extraction. Misalnya pertimbangan dari variasi pilihan makanan dan minuman, sekitar 66,5 persen varians dari variabel pertimbangan variasi pilihan makanan dan minuman bisa dijelaskan oleh faktor yang terbentuk, demikian seterusnya.

\section{Total Variance Explained}

Dari 21 variabel (component) yang dimasukkan dalam analisis faktor, jika masing-masing variabel mempunyai varians 1 , maka total varians adalah $21 * 1=21$. Dengan 21 variabel tersebut diringkaskan menjadi satu faktor, maka yang dapat dijelaskan oleh satu faktor tersebut adalah $37,461 \%$. 
Tabel 4:Total Variance Expalined

\begin{tabular}{|c|c|c|c|c|c|c|}
\hline \multirow[b]{2}{*}{ Component } & \multicolumn{3}{|c|}{ Initial Eigenvalues } & \multicolumn{3}{|c|}{$\begin{array}{c}\text { Extraction Sums of Squared } \\
\text { Loadings }\end{array}$} \\
\hline & Total & $\begin{array}{c}\% \text { of } \\
\text { Variance }\end{array}$ & $\begin{array}{l}\text { Cumula- } \\
\text { tive } \%\end{array}$ & Total & $\begin{array}{c}\% \text { of } \\
\text { Variance }\end{array}$ & $\begin{array}{l}\text { Cumula- } \\
\text { tive } \%\end{array}$ \\
\hline $\begin{array}{l}\text { Variasi pilihan Makanan dan } \\
\text { Minuman }\end{array}$ & 6.540 & 31.145 & 31.145 & 6.540 & 31.145 & 31.145 \\
\hline Rasa Makanan dan Minuman & 3.102 & 14.770 & 45.915 & 3.102 & 14.770 & 45.915 \\
\hline $\begin{array}{l}\text { Presentase Makanan dan } \\
\text { Minuman }\end{array}$ & 2.190 & 10.427 & 56.342 & 2.190 & 10.427 & 56.342 \\
\hline $\begin{array}{l}\text { Ukuran Porsi Makanan dan } \\
\text { Minuman }\end{array}$ & 1.586 & 7.553 & 63.895 & 1.586 & 7.553 & 63.895 \\
\hline Kecepatan Pelayanan & 1.249 & 5.947 & 69.842 & 1.249 & 5.947 & 69.842 \\
\hline Ketepatan Pelayanan & 1.081 & 5.146 & 74.988 & 1.081 & 5.146 & 74.988 \\
\hline $\begin{array}{l}\text { Fasilitas Pemesanan Tempat } \\
\text { Duduk }\end{array}$ & .881 & 4.195 & 79.183 & & & \\
\hline Ketersediaan Pembayaran & .712 & 3.389 & 82.571 & & & \\
\hline Jam Operasional & .665 & 3.168 & 85.739 & & & \\
\hline $\begin{array}{l}\text { Perilaku Karyawan Siap } \\
\text { Membantu }\end{array}$ & .556 & 2.647 & 88.386 & & & \\
\hline $\begin{array}{l}\text { Karyawan yang penuh } \\
\text { perhatian }\end{array}$ & .522 & 2.485 & 90.871 & & & \\
\hline $\begin{array}{l}\text { Penampilan karyawan yang } \\
\text { bersih }\end{array}$ & .341 & 1.623 & 92.494 & & & \\
\hline Daftar menu bersih dan rapi & .323 & 1.537 & 94.031 & & & \\
\hline Kebersihan area & .299 & 1.422 & 95.452 & & & \\
\hline Value for money & .223 & 1.064 & 96.517 & & & \\
\hline Pemberian diskon & .178 & .847 & 97.364 & & & \\
\hline Happy haur & .142 & .676 & 98.040 & & & \\
\hline Pencahayaan yang tepat & .135 & .642 & 98.682 & & & \\
\hline Penataan meja makanan & .123 & .586 & 99.268 & & & \\
\hline Kenyamanan furniture & .090 & .429 & 99.696 & & & \\
\hline Hiburan & .064 & .304 & 100.000 & & & \\
\hline
\end{tabular}

Dari tabel 4. di atas nampak bahwa bila variabel diekstrak menjadi enam faktor, maka diperoleh hasilnya sebagai berikut:Varians faktor pertama adalah 37,461 \%, Varians faktor kedua adalah 4.734:24* $100 \%=19,725 \%$, Varians faktor ketiga adalah 1.638:24 * $100 \%=$ $6.823 \%$, Varians faktor keempat adalah 1.380:24* $100 \%=5.750 \%$, Varians faktor kelima adalah $1.133: 24 * 100 \%=4.721 \%$, Varians faktor keenam adalah $1.030: 24 * 100 \%=4.290 \%$,

Total keenam faktor tersebut adalah $78.770 \%$ yang berarti enam faktor tersebut dapat dijelaskan oleh $78.770 \%$ dari variabilitas kedua puluh empat faktor yang ada. Eigenvalues menunjukkan kepentingan relatif masing-masing faktor dalam menghitung varians kedua puluh empat variabel yang dianalisis. Jumlah angka eigenvalues untuk kedua puluh empat faktor adalah $=24$. Eigenvalues diurutkan dari yang terbesar sampai yang terkecil, dengan kriteria angka eigenvalues di bawah 1 tidak digunakan dalam menghitung jumlah faktor yang terbentuk. Dari lampiran terdapat 6 faktor angka eigenvalues berada di atas angka 1 .

\section{Componen Matrix dan Rotated Componen Matrix}

Factor loading yaitu besarnya korelasi antara masing-masing variabel dengan faktor 1 , faktor 2 , faktor 3, faktor 4 dan faktor 6 . Penentuan variabel masing-masing faktor yang dilakukan dengan membandingkan besaran korelasi pada setiap baris. Angka korelasi di bawah 0,50 
menunjukkan indikasi korelasi yang lemah sedangkan diatas 0,50 berindikasi kuat korelasinya. Componen matrix yang diperoleh disajikan pada tabel berikut:

Tabel 5:Component Matrix

\begin{tabular}{|c|c|c|c|c|c|c|}
\hline Faktor-Faktor Yang Mempengaruhi & \multicolumn{6}{|c|}{ Component } \\
\hline $\begin{array}{l}\text { Potensi Prospek Usaha Jajanan } \\
\text { Malam Hari }\end{array}$ & 1 & 2 & 3 & 4 & 5 & 6 \\
\hline $\begin{array}{l}\text { Variasi pilihan Makanan dan } \\
\text { Minuman }\end{array}$ & .336 & .276 & .496 & -.258 & .361 & -.184 \\
\hline Rasa Makanan dan Minuman & .181 & .611 & .382 & -.243 & .331 & -.112 \\
\hline Presentase Makanan dan Minuman & .187 & .656 & .395 & -.047 & -.117 & -.048 \\
\hline Ukuran Porsi Makanan dan Minuman & -.045 & .693 & .286 & .108 & .119 & .111 \\
\hline Kecepatan Pelayanan & .313 & .732 & -.425 & .108 & -.246 & .033 \\
\hline Ketepatan Pelayanan & .288 & .743 & -.279 & -.194 & -.119 & .312 \\
\hline Fasilitas Pemesanan Tempat Duduk & .740 & .251 & -.383 & .117 & -.019 & -.119 \\
\hline Ketersediaan Pembayaran & .401 & -.020 & -.564 & .241 & .421 & .295 \\
\hline Jam Operasional & .665 & .056 & -.117 & .549 & .213 & -.055 \\
\hline Perilaku Karyawan Siap Membantu & .343 & .342 & -.177 & .506 & .093 & -.467 \\
\hline Karyawan yang penuh perhatian & .428 & -.217 & -.381 & -.472 & .217 & -.137 \\
\hline Penampilan karyawan yang bersih & .850 & -.131 & -.173 & -.212 & .024 & -.198 \\
\hline Daftar menu bersih dan rapi & .658 & -.317 & -.185 & -.242 & .368 & .231 \\
\hline Kebersihan area & .586 & -.324 & .336 & .099 & -.163 & -.301 \\
\hline Value for money & .783 & -.111 & .174 & -.158 & -.187 & .091 \\
\hline Pemberian diskon & .689 & .089 & -.088 & -.130 & -.409 & -.011 \\
\hline Happy haur & .556 & -.321 & .120 & .305 & -.370 & -.010 \\
\hline Pencahayaan yang tepat & .599 & .058 & .037 & -.300 & -.315 & .272 \\
\hline Penataan meja makanan & .643 & -.233 & .432 & .245 & .098 & .338 \\
\hline Kenyamanan furniture & .597 & -.077 & .470 & .309 & .115 & .350 \\
\hline Hiburan & .838 & -.121 & .090 & -.227 & .072 & -.278 \\
\hline a. 6 components extracted. & & & & & & \\
\hline
\end{tabular}

Dari tabel 5 di atas nampak bahwa hubungan setiap variabel terhadap setiap faktor, jika nilai korelasi lebih dari 0,50, maka varaibel tersebut dapat dimasukkan sebagai faktor. Rotated component matrixadalah memperjelas variabel-variabel mana yang masuk ke dalam tiap-tiap faktor. Untuk lebih jelasnya hasil rotated component matrix disajikan pada tabel berikut. 
Tabel 6: Rotated Component Matrix

\begin{tabular}{|c|c|c|c|c|c|c|}
\hline Faktor-Faktor Yang Mempengaruhi & & & Com & hent & & \\
\hline Potensi Prospek Usaha Jajanan Malam Hari & 1 & 2 & 3 & 4 & 5 & 6 \\
\hline Variasi pilihan Makanan dan Minuman & .159 & .152 & -.117 & .764 & .133 & .022 \\
\hline Rasa Makanan dan Minuman & -.033 & .033 & .175 & .835 & .015 & .045 \\
\hline Presentase Makanan dan Minuman & .170 & -.321 & .344 & .618 & .052 & .066 \\
\hline Ukuran Porsi Makanan dan Minuman & -.230 & -.301 & .365 & .548 & .126 & .098 \\
\hline Kecepatan Pelayanan & .116 & -.040 & .832 & .090 & -.144 & .390 \\
\hline Ketepatan Pelayanan & .044 & .101 & .884 & .258 & -.031 & .019 \\
\hline Fasilitas Pemesanan Tempat Duduk & .409 & .367 & .430 & .024 & .081 & .539 \\
\hline Ketersediaan Pembayaran & -.199 & .602 & .304 & -.250 & .323 & .375 \\
\hline Jam Operasional & .193 & .212 & .101 & -.005 & .473 & .702 \\
\hline Perilaku Karyawan Siap Membantu & .094 & -.051 & .109 & .134 & -.035 & .840 \\
\hline Karyawan yang penuh perhatian & .277 & .741 & .003 & -.014 & -.196 & -.010 \\
\hline Penampilan karyawan yang bersih & .660 & .577 & .070 & .080 & .084 & .259 \\
\hline Daftar menu bersih dan rapi & .254 & .787 & .007 & -.017 & .360 & -.018 \\
\hline Kebersihan area & .674 & .025 & -.347 & .072 & .249 & .216 \\
\hline Value for money & .711 & .255 & .113 & .116 & .357 & -.011 \\
\hline Pemberian diskon & .714 & .138 & .358 & -.008 & .082 & .105 \\
\hline Happy haur & .616 & -.078 & -.082 & -.267 & .383 & .215 \\
\hline Pencahayaan yang tepat & .589 & .194 & .379 & .059 & .222 & -.210 \\
\hline Penataan meja makanan & .363 & .112 & -.104 & .103 & .819 & .045 \\
\hline Kenyamanan furniture & .283 & .017 & -.023 & .192 & .830 & .094 \\
\hline Hiburan & .693 & .476 & -.085 & .278 & .136 & .224 \\
\hline \multicolumn{7}{|c|}{$\begin{array}{l}\text { Extraction Method: Principal Component Analysis. } \\
\text { Rotation Method: Varimax with Kaiser Normalization. }\end{array}$} \\
\hline \multicolumn{5}{|c|}{ Rotation Method: Varimax with Kaiser Normalization } & & \\
\hline a. Rotation converged in 12 iterations. & & & & & & \\
\hline
\end{tabular}

Dari tabel 6.di atas nampak bahwa faktor-faktor yang dominan mempengaruhi potensi prospek usaha jajanan malam hari di Kota Medan yang didasarkan pada setiap faktor.

Untuk membuktikan keenam faktor (component) yang yang terbentuk sudah tepat, maka dari tabel 4.7 di bawah ini nampak bahwa angka-angka yang ada pada diagonal, antara Component 1 dengan 1, Component 2 dengan 2, Comonent 3 dengan 3, Component 4 dengan 4, Component 5 dengan 5, dan Comonent 6 dengan 6 terlihat keenam angka jauh di atas 0,50 , dengan demikian keenamp faktor sudah tepat karena mempunyai korelasi yang tinggi.

Tabel 7.Component Transformation Matrix

\begin{tabular}{|l|r|r|r|r|r|r|}
\hline Component & \multicolumn{1}{|c|}{1} & 2 & \multicolumn{1}{l|}{3} & \multicolumn{1}{c|}{4} & \multicolumn{1}{c|}{5} & \multicolumn{1}{c|}{6} \\
\hline 1 & .686 & .436 & .203 & .159 & .409 & .323 \\
\hline 2 & -.184 & -.257 & .699 & .579 & -.164 & .221 \\
\hline 3 & .179 & -.466 & -.420 & .578 & .401 & -.280 \\
\hline 4 & -.221 & -.433 & -.066 & -.313 & .450 & .678 \\
\hline 5 & -.590 & .579 & -.283 & .395 & .206 & .195 \\
\hline 6 & -.256 & .066 & .457 & -.226 & .632 & -.521 \\
\hline \multicolumn{7}{|l}{ Extraction Method: Principal Component Analysis. } \\
\hline \multicolumn{6}{|l}{ Rotation Method: Varimax with Kaiser Normalization. } \\
\hline
\end{tabular}


Dari tabel 7 di atas nampak bahwa semua variabel yang masuk pada tiap-tiap faktor mempunyai korelasi positif, artinya peningkatan loading vaiabel yang bersangkutan semakin mempengaruhi akan pengembangan potensi prospek usaha jajanan malam hari di Kota Medan. Adapun faktor-faktor yang dominan mempengaruhi potensi prospek usaha jajanan malam hari di Kota Medan disajikan pada Gambar dan Tabel 8berikut:

Component Plot in Rotated Space

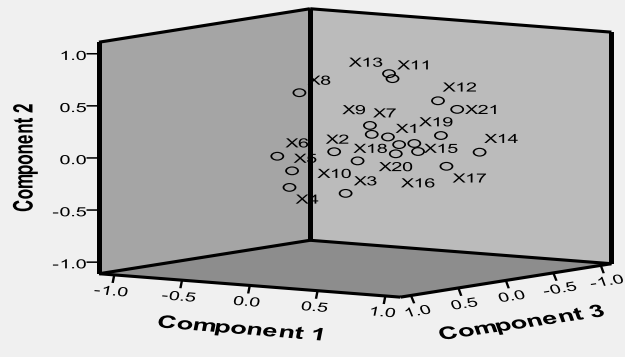

Tabel 8: Faktor Dominan yang Mempengaruhi potensi prospek usaha jajanan malam hari di Kota Medan

\begin{tabular}{|c|c|l|}
\hline Korelasi ${ }^{\circledR}$ & Faktor & \multicolumn{1}{c|}{ Keterangan } \\
\hline$[\mathbf{1}]$ & {$[\mathbf{2}]$} & \multicolumn{1}{c|}{} \\
\hline 0.714 & 1 & Rasa makanan dan minuman \\
\hline 0.711 & 1 & Ketepatan pelayanan \\
\hline 0.693 & 1 & Kebersihan area keseluruhan \\
\hline 0.693 & 1 & Penampilan karyawan \\
\hline 0.693 & 1 & Pemberian diskon \\
\hline 0.671 & 1 & Kenyamanan furniture \\
\hline 0.616 & 1 & Happy hour \\
\hline 0.598 & 1 & Pencahayaan yang tepat \\
\hline 0.714 & 2 & Karyawan yang penuh perhatian \\
\hline 0.787 & 2 & Daftar makanan dan minuman yang bersih \\
\hline 0.602 & 2 & Ketersediaan pembayaran \\
\hline 0.577 & 2 & Penampilan karyawan yang bersih \\
\hline 0.835 & 3 & Kecepatan pelayanan \\
\hline 0.884 & 3 & Value for money \\
\hline 0.835 & 4 & Hiburan \\
\hline 0.764 & 4 & Jenis rasa makanan dan minuman \\
\hline 0.618 & 4 & Presentase makanan dan minuman \\
\hline 0.548 & 4 & Ukuran porsi makanan dan minuman \\
\hline 0.819 & 5 & Pencahaayaan yang tepat \\
\hline 0.830 & 5 & Penataan meja makan \\
\hline 0.840 & 6 & Perilaku karyawan untuk membantu \\
\hline 0.702 & 6 & Jam operasional \\
\hline 0.539 & 6 & Fasilitas reservasi dan pemesanan tempat duduk \\
\hline
\end{tabular}


Dari hasil analisis di atas nampak bahwa kedua puluh dua variabel dapat dikelompokkan kedalam enam faktor. Keenam faktor yang memiliki duapuluh dua variabel memiliki korelasi yang positif, dengan demikian dapat disimpulkan bahwa: semakin memperhatikan keenam faktor yang terdiri dari dua puluh empat variabel, maka potensi prospek usaha jajanan malam hari di Kota Medan akan meningkatkan kunjungan dari wisatwan yang berkunjung atau berada di Kota Medan. Dengan demikian para wisatawan yang bersangkutan akan memperoleh suasana atau kepuasan yang tinggi sehingga mengulangi dan mengajak saudara dan teman yang lain untuk datang kembali ketempat jajanan malam hari yang tersebar di Kota Medan.

\section{Saran}

1. Untuk mendatangkan wisatawan sebanyak-banyaknya adalah jika mampu memenuhi kebutuhan mereka. Oleh karena itu seluruh komponen di dalam obyek wisata harus dikelola dengan baik dan terencana serta didukung dengan koordinasi yang baik, yaitu Koordinasi antar instansi/Dinas di lingkungan Pemerintah Daerah sangat dibutuhkan.

2. Kota Medan dapat menjadi tujuan wisata jajanan malam hari dapat tercapai, diperlukan strategi pengembangan antara lain:

a. Menjaga dan menciptakan rasa makanan dan minuman, misalnya Khas Kota Medan.

b. Meningkatkan kenyamanan dan keamanan wisatawan di sentra-sentra jajanan malam hari.

c. Menjaga dan meningkatkan kebersihan area keseluruhan di sentra-sentra jajanan malam hari.

d. Meningkatkan dan menjaga penampilan karyawan dalam melayani wisatawan

e. Harga makanan dan minuman dibuat murah tetapi kualitas tetap terjaga.

3. Dengan memanfaatkan peluang yang begitu luas, pemerintah daerah Kota Medan diharapkan berperan serta untuk lebih intensif dalam mendukung pengembangan jajanan malam hari di Kota Medan. Adanya kebijakan dan penyuluhan dirasa akan sangat membantu dalam penyempurnaan masakan jajanan malam hari. Selain itu pemerintah daerah perlu juga memfasilitasi pertumbuhan dan pengembangan industri produk wisata jajanan malam hari dengan perangakat pendukung seperti:

a. Peraturan daerah yang dapat mengakomodir kepentingan pengusaha/pelaku jajanan malam hari.

b. Terkait pendanaan pemerintah daerah juga dapat menjadi jembatan dengan membantu rekomendasi pendanaan kepada pengusaha jajanan malam hari melalui koperasi dan bank, salah satunya adalah bank yang dimiliki pemerintah daerah yaitu Bank Sumut. 


\section{DAFTAR PUSTAKA}

Arikunto, Suharsimi. ed. 2002.Prosedur Penelitian Suatu Pendekatan Praktek. Revisi V. Rineka Cipta. Jakarta.

Echols, John M. \& Shadily, Hasan.1993. Kamus Inggris Indonesia. Penerbit PT. Gramedia. Jakarta.

Fandeli, ChafId dan Mukhlison. 2000. Pengusahaan Ekowisata. Fakultas Kehutanan Universitas Gadjah Mada Yogyakarta bekerjasama dengan Unit KSDA DI Yogyakarta dan Pustaka Pelajar.Yogyakarta.

Fandeli, Chafid. 2002. Perencanaan Kepariwisataan Alam. Fakultas Kehutanan Universitas Gadjah Mada. Yogyakarta.

Faulkner, B. 1997.Perkembangan Pariwisata Indonesia: Perspektif "Gambaran Besar". dalam Myra P.Gunawan. ed. Perenconaan Pariwisata Berkelanjutan. Proseding Pelatihan dan Lokakarya.ITB. Bandung.

Gunn, Clare A. 1988. Tourism Planning. 2 Edition. Taylor \& Francis. New York. Husein, Umar. 2003. Metode Riset Perilaku Konsumen Jasa. Ghalia Indonesia.Yogyakarta. http:/ /www pikiran-rakyat.comlcetak./2007/022007/1

7/0902.htm htp://en.wikipedia.orglwiki/Culinarv_profession

Kementerian Kebudayaan dan Pariwisata. 2004. Peningkatan Status Gastronomi Makanan Khas Indonesia dalam festival Boga. Deputi Bid pengembangan Produk dan Usaha Pariwisata. Jakarta.

Kotler, Philip and Armstrong, Gary. 1999. Principles of Marketing. 7th Edition.Printice Hall Inc. Upper Saddle River.

Kotler, Philip. 2000. Marketing Management. Milenium ed. Printice Hall Inc. Upper Saddle River.

Marsum, WA. 1991. Restoran Dan Segala Permasalahannya. Andi Ofset. Yogyakarta.

Mc Intosh, Robert W \& Goeldner, Charles R. 1990.Tourism, Principles, Practices, and Philosophies.John Wiley \& Sons Inc. New York.

Musanef. 1996. Manajemen Usaha Pariwisata di Indonesia. Gunung Agung. Jakarta.

Nasution.2001. Manajemen Mutu terpadu.Ghalia Indonesia. Jakarta.

Nuryanti,Wiendu. 1995. Perencanaan Pembangunan Regional dan Kawasan untuk Kepariwisataan Alam. Dalam Chafld Fandeli. Ed. Dasar-dasar manajemen Kepariwisataan alam. Penerbit Liberty. Yogyakarta.

Pearce, Douglas. 1988. Tourist Development. Second Edition.Longman Scientific \& Technical. New Zealand.

Petunjuk Penulisan Usulan Penelitian dan Tesis.Edisi 2003. Program Pascasarjana Universitas Gadjah Math. Yogyakarta.

Pride, William M. \& Ferrel, O.C. 1995. Penwsaran :Teori dan Prakiek Sehari-hari. Alih Bahasa Daniel Wirajaya. Binarupa Aksara. Jakarta. 
Riduwan.2006. Belajar Mudah Penelitian untuk Guru-karyawan dan Peneliti Pemula.Alfabeta. Bandung.

Sammeng, Andi Mappi. 2000. Cakrawala Pariwisata. Jakarta

Sjahmien, Moehyi. 1992. Penyelenggaraan Makanan Industri dan Jasa Boga.Bhara. Jakarta, Soekadijo, R.G. 1996. Anatomi Pariwisata. Gramedia Pustaka Utama. Jakarta.

Soekresno.2000. Manajemen Food E Baverage Service Hotel. Gramedia Pustaka Utama. Jakarta.

Sugiyono. 2004. Metode Penelitian Administrasi. Alfabeta. Bandung

Sugiantoro, Ronny. 2000. Pariwisata: Antara Obsesi dan Realita. Adicipta Karya Nusa. Yogyakarta.

Supranto. J. 2001. Pengukuran Kepuasan Konsumen. Rineka Cipta. Jakarta.

Triton, P.B. 2006. SPSS 12.0 Terapan Riset statistikparametrik. Andi Offset. Yogyakarta.

Undang-undang No.9 Tahun 1990 tentang Kepariwisataan

Undang-undang No.67 Tahun 1996 tentang penyelenggaraan Kepariwisataan

Voase, Richard. 1999. Tourism: The Human Perspective. Hodder \& Stoughton. London.

Yoeti, Oka A. 1996. Pengantar Ilmu Pariwisata.Angkasa. Bandung. 1997.Perencanaan dan Pengembangan pariwisata. Pradna Paramita. Jakarta.

2001.Strategi Pemasaran Daerah Tujuan Wisata Menyongsong Penerapan Otonomi Daerah. Jurnal Pariwisata Vol 1 Nomor 2. Januari Stiepari YapariAktripa. Bandung.

Zeithami, Valarie A. \& Bitner, Mary Jo. 2000. Services Marketing: Integrating Customer Focus Across the Firm. Second Edition.Mc Graw-Hill Inc. Singapore. 